\title{
Crowd counting: a behavioural economics perspective
}

\author{
Peter J. Phillips ${ }^{1}$ D $\cdot$ Gabriela Pohl ${ }^{1}$ \\ Accepted: 11 February 2021 / Published online: 19 February 2021 \\ (c) The Author(s), under exclusive licence to Springer Nature B.V. part of Springer Nature 2021
}

\begin{abstract}
Developments in technology have facilitated the emergence of new crowd counting organisations. Some of the organisations have established platforms to disseminate their data, making it available to researchers for the first time. These databases promise to increase the quality and quantity of research in various fields. In the late 2010s, specialist crowd counting organisations emerged with the sole purpose of counting crowds at protests and disseminating the results, sometimes in a purely partisan manner. Because of the contemporary relevance of protest behaviour, we frame our discussion within this context. For social scientists considering the utilisation of these new databases, it is essential that crowd numbers be linked to underlying human behaviour in a way that promises a chain of connections to investigate and explore. We use behavioural economics to show why relative crowd size may be important for human decision-makers. And we show how the significance of relative crowd size relates to other aspects of the human decision-making process, including risk preferences and probability assessments. Far from being a theory of protest behaviour, we present a behavioural economics-based primer for empirical researchers and social scientists engaging with newly available crowd counting data. The conclusions may apply in other contexts and might be extended to encompass specific types of behaviour, including aggression and violence. Indeed, the conclusions may guide the analysis of the emergence of the crowd counting organisations themselves.
\end{abstract}

Keywords Crowd counting $\cdot$ Behavioural economics $\cdot$ Relative crowd size $\cdot$ Protests $\cdot$ Decision-making

\section{Introduction}

Why was President Trump's rally in Tulsa, Oklahoma, in June 2020 deemed to be a failure? An important reason was because it failed to fill the venue $(19,000$ seats $)$ despite earlier reports of 1,000,000 ticket requests. The 'full stadium' had become the reference

Peter J. Phillips

phillips@usq.edu.au

Gabriela Pohl

gabriela.pohl@usq.edu.au

1 Faculty of Business, Education, Law and Arts, University of Southern Queensland, Toowoomba, QLD 4350, Australia 
point. If the Trump campaign people had, instead, suggested that a crowd of 2000 people would be a good turnout because of the Covid-19 pandemic, how would the actual turnout of around 6000-7000 have then been judged? Later in 2020, as the US Presidential Election neared, at his rallies or 'peaceful protests', President Trump would chide the television news networks for broadcasting only the stage and podium area rather than panning out to show the full extent of the crowd. Why was it so important, from Donald Trump's perspective, that the television networks show images of how many people were attending? It is in the answers to these types of questions that we find the potentially deep narratives about human decision-making and behaviour to be explored through an empirical analysis facilitated by the emergence of new crowd counting technologies, organisations and databases. In this paper, we use behavioural economics as a primer to show why relative crowd size may be important for human decision-makers who participate in protests and how the significance of relative crowd size is connected with other aspects of the human decisionmaking process, including risk preferences and probability assessments. This may help provide some of the methodological foundations for empirical analysis seeking to engage with new developments in crowd counting technology, crowd counting organisations and the data that they disseminate.

In many ways, the story of this paper begins in 2017. On August 12, what would become known as the Charlottesville protests took place. In the remaining four months of 2017, there were more than 350 Charlottesville-related protests involving more than 60,000 people across most states of America (Boston University 2017). The interesting thing about these protests and all those that have taken place since, is the prominence that has been accorded to relative crowd numbers. A highly charged political context combined with the development of new crowd counting technology has seen the use of the term 'crowd counting' grow exponentially since $2010 .{ }^{1}$ The general interest in crowd counting-including but not limited to protests and social movements-is reflected in the emergence and growth of new techniques (including algorithms), new databases and new crowd counting organisations. ${ }^{2}$ Some of these organisations are devoted solely to counting crowds associated with protest movements. Some of these organisations are partisan groups that count for just one side of a protest movement. ${ }^{3}$ These partisan political groups use their measurements of relative crowd sizes to highlight the popularity (or unpopularity) of a particular movement or event.

Indeed, a unique feature of the present political context is the collection, archiving and online dissemination of relative attendance data by recently established crowd counting organisations (or crowd counting organisations making use of newly available technologies). An example is an organisation called Count Love. This is a partisan organisation that counts and reports protester numbers at anti-Donald-Trump-policy demonstrations. Another example is the crowd counting consortium (CCC), which is a non-partisan platform collecting data on all types of protests, providing elaborate analytics, interactive charts and maps. These emerging and potentially persuasive forces complement the

\footnotetext{
1 See Google's Ngram Viewer.

${ }^{2}$ Companies such as CrowdVision and Cohera-Tech count crowds for commercial clients (e.g. shopping centres and museums). These are part of the story of the growth in interest and technology development around crowd counting but we are not specifically interested in these organisations.

${ }^{3}$ Counting protester numbers is where our interest lies. We discuss the Crowd Counting Consortium and Count Love. The latter is a one-sided counting organisation, set up to count numbers at protests on one side of a particular issue and not both sides of that issue (i.e. not the total crowd).
} 
growing sophistication of protest databases that have traditionally operated out of universities. Relative crowd numbers might be more relevant than before because the numbers can be counted, disseminated, shared, analysed and archived like never before.

We argue that the key starting point for empirical researchers seeking to utilise crowd counting data for social scientific studies is the significance of relative outcomes or payoffs vis-à-vis absolute outcomes or payoffs to human decision-makers. Why are relative payoffs so important? A part of the answer is that measuring gains and losses against a reference point is a fundamental feature of human decision-making. The framing of outcomes as gains and losses against a reference point shapes the way that people feel about their experiences and influences the decisions they make going forward. High absolute payoffs are important but payoffs that are above a reference point are even more important because it is relative to a reference point that gains and losses are assessed. It is not enough, especially in a political context where there are regular protests on both sides of many issues, ${ }^{4}$ to claim that many people turned out for a particular cause on a particular day. A high crowd number might be framed as a loss if it fails to surpass a reference point and vice versa. And that reference point might be the number of people who turned out to support the opposing view or it might be an aspiration formed and advertised by one side or the other. The crowd at President Trump's Tulsa rally was assessed against an extremely optimistic reference point and it was consequently framed as a loss. The possibility that the same turnout might have been framed as a significant gain had the reference point been different is an important implication of the theoretical work that we describe herein.

In the sections that follow, we explain the relevance of outcomes measured not absolutely but against a reference point and we describe the connections between reference point dependence and several other features of human decision-making. Our primary theoretical framework is Kahneman et al. (1979) prospect theory. When facing risk and uncertainty, people evaluate their alternative courses of action by assessing the outcomes that might be experienced and the likelihood of those outcomes. This is fundamentally analogous to rational choice theory (or, more precisely, expected utility theory) but with the important difference that the decision-maker's choices are buffeted away from perfect rationality by various factors that are inherent in the decision-making process. Several of these factors constitute the core of prospect theory:

1. People assess outcomes as gains and losses against a reference point, not in absolute terms.

2. When people expect to experience gains (or after they have experienced gains), they behave more conservatively and take fewer risks.

3. When people expect to experience losses (or after suffering a loss), they behave less conservatively and take greater risks to avoid or recoup their losses. This is because they are loss averse.

4. Changes in outcomes that are more distant from the reference point capture less of the decision-maker's attention and exert relatively little influence over the decision-making process.

5. When assessing the likelihood of experiencing an outcome, people tend to overweight unlikely outcomes and underweight more likely outcomes.

\footnotetext{
${ }^{4}$ The crowd counting consortium (CCC) estimates that up to 9 million people protested in the United States during 2017.
} 
Prospect theory describes a human decision-making process where the task of ordering and ultimately choosing from among alternative risky courses of actions is shaped by the decision-maker's reference point. This is the perspective from which all outcomes are viewed and assessed as either gains and losses and it is here that we shall find the connection between the human decision-making process and relative outcomes, including relative crowd sizes. But the reference point, central though it may be, is just one of a set of interconnected factors that shapes the way in which people weigh up their options and choose what they think is their best course of action. The dynamics of choice are such that they depend on the gains and losses that are expected and experienced. The reference point can be formed by the decision-maker's own past achievements or the achievements of others, including rivals. The reference point may also be an aspiration or a goal. As gains and losses unfold, risk preferences and loss aversion exert their influence over subsequent decisions. The importance to decision-makers of relative outcomes, gains and losses measured not absolutely but relative to a reference point, is connected in a deep way to the human decision-making process. The study of relative crowd sizes, therefore, promises a chain of connections to investigate and explore. Combined with other data sets, new avenues for empirical analysis are emerging along with developments in crowd counting technology, crowd counting organisations and the platforms used to disseminate the counts.

\section{Politics, protests and crowds}

Disputes over the size of mass protests have become routine. Organisers want to highlight widespread commitment to their cause and distrust conservative estimates by the media and police. More accurate counts probably will not end these disagreements but will provide better evidence amidst the partisan squabbling. ${ }^{5}$

Because of the contemporary interest in political protest movements and the emergence of partisan crowd counting organisations, which itself might find its explanation in the theoretical frameworks that we describe, we have chosen protests and 'politics' more generally, as the context around which to frame our discussion. This is not a theory of protest behaviour, though some of the insights of behavioural economics are no doubt relevant. Our primary objective is to explain the deeper narratives about human decision-making that can be connected with a study of crowd counting to show that crowd counting is more than just a way to monitor participation or the popularity of a protest movement, political candidate, sporting code etc. As a starting point, we need to show that crowd sizes and specifically relative crowd sizes are important to people who organise or participate in protest movements and social movements more generally. Fortunately, the evidence is abundant.

Up until relatively recently, the media and the police were the primary source for crowd number estimates. For example, the Baltimore Sun carried a story on September 301991 entitled 'Pro-Choice, Anti-Abortion Protesters Clash in N.Y.'. The article opens:

NEW YORK - About 1,200 opponents of abortion formed a vast, sparse human cross on Fifth Avenue and 34th Street in midtown Manhattan yesterday, but their quiet protest was overwhelmed by 4,000 militant abortion-rights demonstrators who marched down their ranks and engulfed them in a roar of chants, shouts and anger.

${ }^{5}$ McPhail et al. (2004, p.12). 
"New York is pro-choice! New York is pro-choice!" the marchers chanted again and again, waving a profusion of signs as they moved down Fifth Avenue in a throng five blocks long and rounded the corner of 34th Street to confront the main body of abortion opponents in the shadow of the Empire State Building.

In recent years, even relatively small scuffles and skirmishes between opposing sides have attracted the attention of the press. And situations where protests have been cancelled, sometimes because of planned counterdemonstrations, have become newsworthy nonevents. Many media reports either explicitly report relative crowd sizes or imply that one side outnumbered the other. For example, the Irish Times reported on January 192019 in Belfast, that a planned demonstration by a group calling itself the Yellow Vest Movement of Great Britain was cancelled after left-wing activists arranged a counter-protest (Irish Times 2019). ${ }^{6}$ On the same day in New York City, CBS News reported that Women's March NYC, an event organised by Women's March Inc. clashed with a competing march organised by the Women's March Alliance (CBS News 2019). And a few weeks earlier in Australia, the ABC News reported on how police struggled to keep a rally of hundreds farright protesters separate from a counter-rally of anti-fascist protesters (ABC News 2019).

These themes resonate through the titles of news pieces appearing throughout the spring and summer of 2018: (1) ABC News America, August 30 2018: Tensions High in Germany Where Far Right Protests on Thursday Will Be Met With Counter Demonstrations (Hucal 2018); (2) Aljazeera, May 27 2018: Counter-Protesters Outnumber Far Right AFD Rally in Berlin (Aljazeera 2018); (3) Telegraph UK, May 13 2018: White Nationalists Drowned Out By Counter-Protesters in Washington Rally (Allen 2018); (4) PBS America April 4, 2018: Right Wing Rally, Counter-Protesters Face Off in Portland (PBS America 2018). However, despite this brief window of intense interest, the national press is generally unwilling to allocate resources to the coverage of smaller protests and counter-protests and other newsworthy events easily sweep reports submitted by local affiliates off the front-pages (and webpages).

In 2020, as the US Presidential Elections neared, the relative size of crowds attracted to Donald Trump's rallies versus those attracted to Joe Biden's rallies became a major talking point. A typical Trump rally was held in the open air on airport runways all around the country. Trump would arrive on Airforce One, disembark and deliver his speech directly to the crowd. The very nature of the approach contrasted the Trump administration's policy stance on the gathering of crowds during the Covid-19 pandemic with the Biden campaign's consistent messaging on social distancing. This introduced an interesting dimension to the inevitable comparison of crowd sizes. There was no question, as anyone comparing a Trump rally with a Biden rally could see, that Donald Trump was attracting a vastly greater number of attendees to his rallies. Supporters of President Trump, of course, pointed to the differential in turnouts as evidence of the President's overwhelming popularity. However, while the Biden campaign could not argue over the numbers, supporters of the former Vice President pointed to the difference in campaign strategies, with the Biden campaign arguing that the difference in crowd sizes reflected, not popularity, but the more responsible approach of Joe Biden to the pandemic. Given the stark difference in crowd sizes and, consequently, the absence of a debate over relative crowd sizes, political commentary became focused on the debate over the interpretation of the relative crowd sizes (e.g. Reuters 2020; Shear et al. 2020; Nakamura 2020). This is interesting because it illustrates how easily

${ }^{6}$ Also see BBC News, January 272019. 
crowd sizes can make their way to the centre-stage of political debate. We might even say that relative crowd size is a heuristic, used to generate a 'fast-thinking' conclusion about the relative success of an undertaking, including a political campaign.

The Presidential Election certainly had a significant pandemic-related narrative, shaping not only policies but the look and feel of the two campaigns. As 2020 wore on, the Covid19 restrictions put in place by governments around the world were themselves the target of protests. And the relative crowd sizes were once more a primary focal point for reporters, sometimes measured against the aspirations or targets set by organisers and sometimes to compared to other social movements. At times, media outlets criticised their competitors for making too much of lockdown rallies. An example of a comparison of actual turnout with the stated aspirations of organisers was printed in Der Spiegel:

Corona-Proteste in Berlin Faktencheck zur Teilnehmerzahl: Laut Polizei kamen knapp 40.000 Demonstranten zu den Corona-Protesten nach Berlin. Die Veranstalter sprachen von Hunderttausenden oder gar von mehr als einer Million Teilnehmern. Welche Zahl stimmt denn nun? ${ }^{7}$

An example of disagreement between reporters at rival media outlets is the criticism of Washington Post reporters Olorunnipa et al. (2020) by Vox's Chenoweth et al. (2020). On April 18, the Washington Post reporters (Olorunnipa et al. 2020) ran a story under the headline, Rallies Against Stay-at-Home Orders Grow as Trump Sides with Protesters in which they implied a growing resistance against lockdown measures in the United States. In response to this Washington Post article and others by the New York Times, Vox's reporters (Chenoweth et al. 2020) had the following to say a few weeks later, under the title Media Coverage has Blown Anti-Lockdown Protests Out of Proportion:

The social distancing protests have also drawn modest crowds, with between 35,000 and 47,000 total attendees reported across all events combined through May 3. In comparison, a single protest against the governor in Guaynabo, Puerto Rico, brought out upward of 250,000 on July 21, 2019. Hundreds of thousands turned out for PRIDE marches in June 2019 and the September 2019 climate strike. The Lights for Liberty protests exceeded 100,000 and December's pro-impeachment rallies exceeded 75,000.

Interestingly, Vox's piece not only criticises the Washington Post for the implications they had made about crowd sizes in support of ending the pandemic related lockdowns, the Vox reporters also took the opportunity to compare the crowd sizes at these anti-lockdown protests with the crowds that had turned out for unrelated events (there being, of course, no pro-lockdown rallies against which to make a direct comparison of rival or opposing points of view). These examples highlight the importance of relative crowd size in the contemporary political context. While we have focused on protests and rallies, the discussion could be expanded to encompass television ratings for liberal and conservative cable news shows (e.g. Tucker Carlson or Sean Hannity on Fox News versus Rachel Maddow on MSNBC). While absolute viewership is obviously important for advertising revenue, the rankings tables compare the channels and shows with each other. And, of course, the discussion could be expanded beyond the political context altogether to encompass rivalries between sporting codes (or leagues) and social media platforms to name just a few. However, some

7 Dambeck (2020). 
of the interest in attendances and television ratings for sporting codes now has a political dimension as too does the relative number of users on different social media platforms (e.g. Parler versus Twitter), indicating that perhaps the implications of our discussion are broader than one might first expect.

\section{Reference points and relative gains and losses}

The importance of relative outcomes or payoffs to human decision-makers is a nuance that is difficult to fit into an orthodox economic analysis. An orthodox analysis in the sense of von Neumann et al. (1947) deals solely with absolute gains and losses. All positive outcomes or payoffs are classed as gains and all negative outcomes are classed as losses. But people do not always think in such absolute terms. They sometimes view a positively valued outcome (e.g. a prize of some sort) as a loss while at other times they view a negatively valued outcome (e.g. a negative investment return) as a gain. Kahneman et al. (1979) ${ }^{8}$ prospect theory, which is a descriptive model of decision-making under conditions of risk and uncertainty, is a much more suitable model with which to explore the importance of relative outcomes or payoffs because it is based on the idea that the decision-maker frames outcomes as gains and losses by comparing them to a reference point.

When deciding from among a set of alternative courses of action, the decision-maker depicted in both orthodox and behavioural economics proceeds by evaluating the outcomes, determining how much utility or value he or she associates with them. In orthodox economics, utility is calculated by entering the outcome or payoff into the decision-maker's utility function. Negatively valued outcomes (e.g. - 10) are entered into the utility function as negative values and positively valued outcomes (e.g. +10$)$ are entered into the utility function as positive values. Unlike an orthodox utility function, which is everywhere concave for a risk averse decision-maker, the prospect theory value function ${ }^{9}$ inflects about the reference point, delineating a domain of losses and a domain of gains, producing an $\mathrm{S}$-shaped value function with risk seeking and risk averse segments, as shown in Fig. 1. It was this eye-catching function that captured the attention of Richard Thaler. He would later draw heavily on prospect theory in his quest to build behavioural economics (Thaler 2016; Barberis 2018).

In prospect theory, utility or prospect value is calculated by entering the outcome or payoff into the value function. The difference between the orthodox approach and the prospect theory approach is that it is not the outcomes themselves that are entered into the value function but the change relative to a reference point. If the reference point is 5 , then a positively valued outcome (e.g. +10$)$ enters the function as $10-5=5$ and a negatively valued outcome (e.g. -10 ) enters the function as $-10-5=-15$. If the reference point is -20 , a negatively valued outcome such as -10 enters the value function as $+10(-10$ $--20=10) .^{10}$

\footnotetext{
8 Tversky et al. (1992) presented a revised and finished form of prospect theory. See Barberis (2013) for a review and summary of prospect theory and its application in economics.

9 Kahneman \& Tversky deliberately avoid using the term 'utility'. The value function is, however, a variant of an orthodox utility function.

10 This can happen, for example, when a person expects a cost of $\$ 500$ only to learn that the actual cost will be $\$ 200$. While still a cost, the $\$ 200$ represents a \$300 'gain' relative to the reference point.
} 


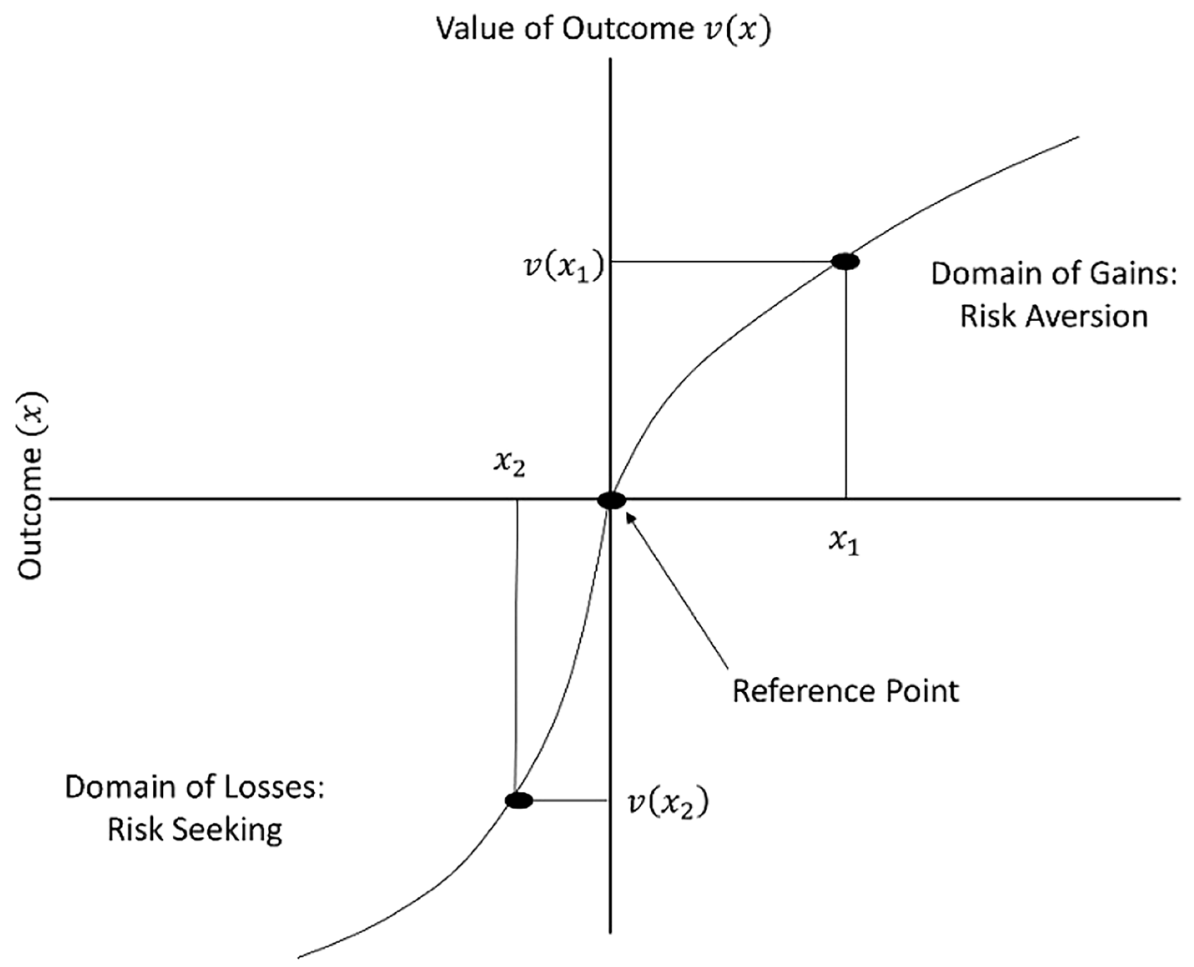

Fig. 1 Prospect theory's S-shaped value function

According to prospect theory, when a decision-maker evaluates outcomes, the position of the reference point determines whether those outcomes are framed as gains or losses. A positive outcome might be framed as a loss if it lies below the reference point and vice versa. This is significant because people feel and act very differently depending on whether they find themselves in the domain of losses or the domain of gains. Thaler (1985, p.202), explains:

1. As a preliminary principle, people try to frame outcomes in a way that makes them feel happiest.

2. If there are many small gains, people like to think of them separately (e.g. Christmas presents wrapped separately rather than in a single parcel).

3. But if there are many small losses, people would rather think in terms of one larger loss.

4. When a situation yields a mixture of gains and losses, people like to segregate the gains and combine the losses.

5. And because prospect theory implies that 'losses loom larger than gains' (loss aversion), people usually have to be offered much more to give something up once they have it than they themselves would have offered to acquire it in the first instance.

Reference dependent decision-making has significant implications for human behaviour, even when the reference point is defined simply as the status quo. A prominent example 
is the adoption of prospect theory within a part of the international relations discipline. In fact, international relations scholars were among the first adopters outside of economics, using prospect theory to explain and guide government decision-making past and present. ${ }^{11}$ They depict situations in which one nation state seeks to change the status quo and they explore the ensuing interactions among competing nation states, some of whom want to establish a new status quo of their own or maintain the existing status quo. While this has been exceptionally useful in helping scholars to explain decision-making at critical points in modern history (e.g. during the Cuban Missile Crisis), the reference point concept itself has evolved, expanding away from a status quo interpretation to encompass goals and aspirations. Lopes (1987) and Heath et al. (1999), for example, made the reference point an aspiration or goal towards which the decision-maker aims and, in the process, reshaping the dynamics of the decision-making process. The concept was also given a social dimension by those who saw the origin of the reference point in the achievements of predecessors, rivals, or idols (Phillips et al. 2014).

Prospect theory embeds a much more nuanced framing of gains and losses than orthodox decision theory. The position of the reference point determines gains and losses and even positive outcomes will be framed as losses if they fall below the reference point. This is not just a gain-loss calculus. As we explain in the next section, reference point dependence is connected to other important aspects of the decision-making process. Prospect theory and behavioural economics highlight the sensitivity of human decision-makers to changes in relative values rather than absolutes and helps us to understand the deeper meaning and motivation for outcome framing in different contexts. If relative crowd sizes are important to decision-makers, we can use prospect theory and behavioural economics as a framework to guide our empirical analysis of crowd data and, beyond identifying trends and magnitudes, combine crowd data with other relevant datasets to explore deeper connections wherever relative crowd sizes hold significance for decision-makers. It is to these connections that we now turn.

\section{Risk preferences, aspirations and decision-making dynamics}

Risk preferences, not surprisingly, have a lot to say about the outcome of a person's decision under conditions of risk. Orthodox expected utility analysis treats decision-makers as being risk averse. They will accept more risk, only if they are compensated with a commensurate increase in expected payoffs. The dynamics, such as they are, relate to how a person's risk aversion changes as their payoffs accumulate. For example, if constant relative risk aversion (CRRA) is assumed, the decision-maker maintains a steady proportional allocation of resources to risky activity as payoffs accumulate. Alongside this, however, the decision-maker is usually assumed to exhibit decreasing absolute risk aversion (DARA). While the proportional engagement remains the same, the absolute amount of resources allocated with risky activity increases as payoffs accumulate. CRRA and DARA work backwards and forwards, indicating that a person's risk aversion changes as their accumulated payoffs rise and fall. Of course, accumulated payoffs are measured absolutely. If they

\footnotetext{
11 See Levy (1992, 1996, 1997) who developed the first applications that have since been applied to various problems, including the historical analysis of the decision-making processes applied by both sides during the Cuban Missile Crisis (Haas 2001), the Suez Crisis (Richardson 1993), the Iranian hostage crisis rescue mission (McDermott 1992) and Soviet policy towards Syria prior to the Six Day War (McInerney 1992).
} 
are positive, the person has experienced a gain. If negative, the person has experienced a loss.

Prospect theory expands this connection between risk preferences and accumulated payoffs in two ways. First, the sum of accumulated payoffs is not measured absolutely but relative to a reference point. As such, a person will approach a new risky decision as more or less risk averse depending not only on his or her sum of accumulated payoffs ${ }^{12}$ but on how this accumulated sum compares to the reference point. Second, recognising that people are loss averse in the sense that a loss of some magnitude is felt more than a gain of the same magnitude and are willing to take risk to avoid losses, Kahneman et al. (1979) used the reference point to delineate a domain of losses in which the decision-maker is risk seeking and a domain of gains in which the decision-maker is risk averse (Fig. 1).

When considering his or her alternatives, the person's choice will be shaped by whether the decision-maker's accumulated payoffs place him or her in the domain of losses or in the domain of gains relative to the reference point. If the decision-maker is in the domain of gains, he or she will be more conservative and try to consolidate that position. If the decision-maker is in the domain of losses, he or she will be willing to take risks to extricate himself or herself from that position. The important thing to note is that the decision-maker might, on the appearance of things, be well positioned. However, if he or she has set a very ambitious goal, what appear to be substantial gains might be perceived by that decisionmaker as losses, leading to a degree of risk seeking that would surprise us if we expected the decision-maker to behave conservatively and consolidate what, if measured absolutely, are solid gains.

In addition to being the standpoint from which outcomes are evaluated as gains or losses, the reference point also acts as a focal point. When considering alternative risky courses of action, changes in outcomes further and further away from the reference point are less important to the decision-maker than changes in outcomes that are closer to the reference point. This scaling of outcomes relative to the reference point results in diminishing sensitivity. Let us assume that an organiser has a reference point of 100 attendees. He is deciding between two locations. Let us say that he receives news that one location might be subject to some council bylaws that would impose a fee on his organisation if the crowd was to exceed a 2000-person capacity by 500 people (i.e. a total crowd of greater than 2500). This would have little impact on his location decision because 2000 is distant from his 100-person reference point. On the other hand, if he receives news that one location might deploy a police presence should the crowd size reach 150 and that this plan is likely to discourage attendance, perhaps reducing turnout to 80 or less, it would have a proportionally bigger impact on his choice between the two locations. Events do not operate in a contextual vacuum and anticipated crowd sizes are by no means detached from a broader set of considerations that might be appended to crowd counting data to develop a more detailed picture of the connection between various factors.

Every risky decision requires not only an assessment of the possible outcomes but the likelihood that a particular outcome will be experienced. Expected utility theory requires the possible outcomes of each risky alternative course of action to be weighted by their probability of occurrence. This implies a linear probability weighting function. Kahneman et al. (1979), however, found that people tend to overweight unlikely

\footnotetext{
12 We avoid using 'wealth' because the payoffs allowed within the expected utility and prospect theory frameworks do not have to be monetary. Using monetary terms like wealth obscures this important fact and restricts the apparent applicability of the theories.
} 


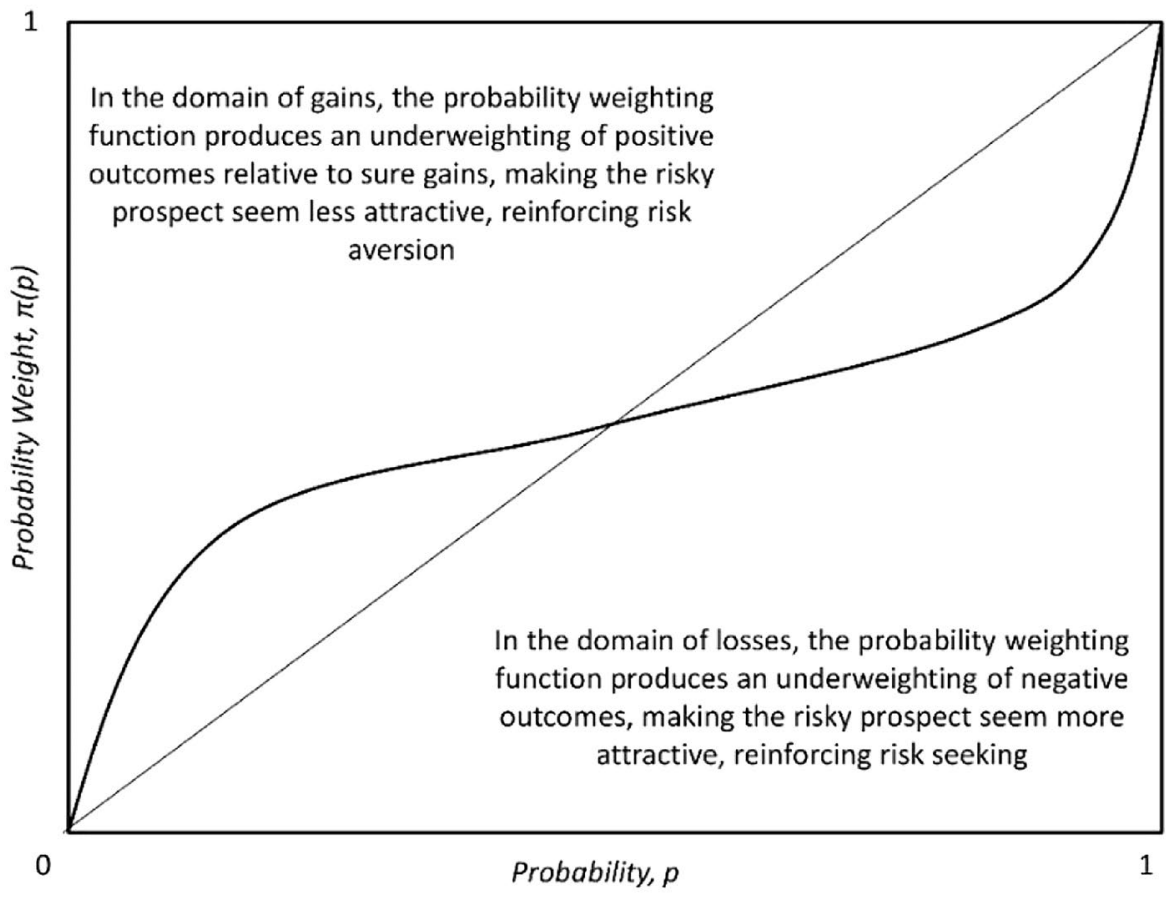

Fig. 2 The inverse S-shaped probability weighting function

outcomes and overweight likely outcomes because their attention is drawn towards very likely or very unlikely outcomes, distorting their perception of the likelihoods that they subsequently attach to each possible outcome. This results in an inverse S-shaped probability weighting function (Fig. 2) which interacts with the S-shaped value function to reinforce risk aversion in the domain of gains and risk seeking in the domain of losses.

How can perceptions of gains and losses, denominated in terms of crowd sizes relative to a reference point, shape the motivation of organisers and participants? Heath et al. (1999) were among the first researchers to use prospect theory to shed more light on the psychology of goals. Why are people more motivated when they are close to achieving a goal? And why do people with higher goals feel worse when they fail to reach their goals? These issues had been debated for many years (see Garland 1984; Klein 1991). Heath, Larrick et al. (1999) provided some plausible answers for these question by treating goals as reference points. If progress towards a goal is evaluated along the $\mathrm{S}$-shaped value function, motivation increases (decreases) closer to (further away from) the reference point because of increasing (diminishing) sensitivity. Loftier goals expand the domain of losses, increasing the likelihood that the failure to achieve the goal will be framed as a significant loss.

Whereas the media and, to a certain extent, the police once had a virtual monopoly on crowd counting and reporting, this is changing rapidly and the implications of this change, bringing with it as it does new technologies and data, represents an opportunity for empirical analysis. The methodological and theoretical underpinnings of such may draw on decision theory in the manner we have explained. People frame outcomes as 
gains and losses relative to a reference point. The reference point might be a previously achieved outcome, it might be an outcome achieved by a rival or it might be an aspiration. Following an event, gains and losses are recorded. We can note that even a high turnout (or viewership or subscribership etc.) may be perceived as a loss. This adds a degree of subtlety to the ways in which we might discuss the importance of crowd size but it is when we begin to glimpse the ways in which behavioural economics and prospect theory might be applied to decision-making dynamics that the real potential for such applications begins to become clear. This is especially the case when we are trying to unravel the potential implications of innovations such as the emergence of crowd counting organisations and the wider and faster dissemination of relative crowd sizes, possibly in a wholly partisan manner.

\section{Connecting the empirical analysis of crowds with a bigger conversation}

It is likely that the type of empirical analysis that we envisage will focus on social movements, since this is by far the largest research program with an established connection to crowd counting (as exampled by the selection of press stories listed towards the beginning of this paper). Social movements seem to ride a wave of success sparked by easy victories on issues that already have a lot of public support towards mobilisation on more difficult issues and, ultimately, declining motivation to mobilise as things become more and more difficult (see Koopmans 1993, p.655). We can fit some of these dynamics into a prospect theory framework that could be explored empirically by using crowd counting data in combination with other relevant datasets. We assume, in keeping with our focus on crowd numbers, that organisers and participants have in mind a crowd size goal or aspiration and that this is the reference point against which outcomes are evaluated as gains or losses. The first event takes place and a turnout number is determined and disseminated (now more quickly and more widely than in the past). According to prospect theory, what happens next?

Sometimes organisers will state a turnout goal explicitly. ${ }^{13}$ This might be 'internal' (i.e. something the organisers want to achieve, such as a million attendees). Sometimes, the reference point might be external (e.g. to achieve a bigger turnout than an opposing movement achieved at a previous event). People with higher goals are more motivated and perform better. And people who find themselves in the domain of losses work harder to get themselves out of it. Prospect theory decision-makers are loss averse. They feel losses more than gains of the same magnitude. As such, a high goal is motivating but failure to achieve it is felt more acutely. The first thing that we might say, therefore, is that the original goals that characterise a movement are critical to the framing of its future successes and failures. If Koopmans (1993) is correct in saying that movements ride a wave of small victories, then we might assume that a relatively modest goal is set in the first instance. While a modest goal might not produce highly motivated behaviour, it does ensure that the domain of gains is relatively wide and that deep losses are less likely. As such, if the goal is not achieved first time out, it will not be a particularly demotivating experience.

\footnotetext{
13 While we are focused on relative crowd sizes, it is important to consider the implications of the following discussion for any goals that a social movement might set for itself.
} 
Once a goal is set, an event takes place. Relative to the reference point, gains and losses are recorded. The supporters of the movement are now in either the domain of losses or the domain of gains. This activates one of two behavioural characteristics incorporated in prospect theory: (1) people are risk seeking in the domain of losses; and (2) people are risk averse in the domain of gains. If the movement experienced a small loss, the goal is still within reach, supporters are motivated to reduce the unpleasant feelings stemming from loss aversion and they are willing to take more risks in pursuit of their goals. Sooner or later, however, a successful movement will record the easy gains that Koopmans (1993) refers to. This might have a demotivating effect because both organisers and supporters no longer experience the unpleasantness of a goal that remains just out of reach. These types of dynamics emerge naturally from prospect theory.

Crowd counting and the innovations that we have been referring to connect with longstanding concepts in the sociology of social movements, including mobilisation (Ferree et al. 1985; Lane 1962; Parkin 1971 and Kluegel et al. 1983), contagion and diffusion of protest movements (Denardo 1985; Myers 2000; Gleditsch et al. 2015), the framing of a social movement (Benford et al. 2000; Andrews 2002) and ideology and emotion (Mattick 1968; Spilerman 1970, 1971, 1976). All these things are part of a very complex picture that researchers have been trying to piece together for a long time.

Perhaps the best-known economic theorist (within economics) to write specifically on the theory of protest behaviour is Kenneth E. Boulding. His 'Towards a Theory of Protest' (1967) sketches his ideas about how a theory of protest would be built. Unfortunately, having been published in a relatively obscure journal outside of the mainstream of economics discourse, this article has been little cited and appears not to have had any impact at all on the economic analysis of protest. More successful ${ }^{14}$ but not directly so was Thomas C. Schelling, with his book 'The Strategy of Conflict' (1960), his article, 'Dynamic Models of Segregation' (1971) and his later book 'Micro-motives and Macro-behaviour' (1978). In these pieces, he introduced at least two important analytical tools that were later used by protest theorists: (1) focal points; and (2) cascades (see, for example, Karklins et al. 1993; Pearlman 2018).

Much more successful and in a more direct way in shaping the development of a theory of protest and protest behaviour, was Mancur Olson's 'The Logic of Collective Action' (1965). Olson's work has had a significant impact on the study of protest movements and is much cited within the sociology literature. Olson argued, somewhat provocatively, that large groups will fail, while small groups will succeed (Hardin 1982, p.38). Based on concepts that are familiar to economists, especially public goods and the free-rider problem, Olson's work initiated a large follow-up research program aimed primarily at confirming or disputing his argument about group size (for example, see Chamberlin 1974; Frohlich et al. 1970; McGuire 1974; and Oliver et al. 1988). In addition, his rational choice or cost-benefit calculus approach to collective action has formed the basis for a rational choice theory of protest behaviour.

Like other areas of study, notably criminology where Becker's (1968) rational choice approach continues to shape the field, the influence of economic theory can be found, even though economists have not themselves devoted a great deal of attention to protest behaviour. ${ }^{15}$ Francisco (1993, p.664) explains that protest research has been dominated by two

\footnotetext{
${ }_{14}$ We are speaking only of influence on the theory of protest and protest behaviour, not generally, of course.

15 Apart from the analysis of certain protest types, especially labour strikes (Ashenfelter et al. 1969; Kennan 1986; Card et al. 1995).
} 
approaches: (1) an older, traditional approach which sees protest behaviour as inextricably linked to deprivation or inequality (e.g. Zeitlin 1966; Marx 1967; Pinard 1967; Muller et al. 1987); and (2) a newer rational choice approach which sees protests emerging from opportunity and expected utility considerations (e.g. Opp 1989; Muller et al. 1990; Muller, Dietz et al. 1991; Leighley 1995; Meyer et al. 1996; Finkel et al. 1998; Luders 2006). ${ }^{16}$

Beginning in the 1960s with contributions by Wilson (1961, 1973) and Lipsky (1968) and culminating in Gamson's (1975) 'The Strategy of Social Protest', the outlines of protest theory from a sociological perspective were gradually put in place. ${ }^{17}$ Together with the development of databases that would allow the study of the intensity and frequency of protests (see Herkenrath et al. 2011), these theoretical foundations have facilitated an ongoing discourse. The early work was a response to the protest movements of the 1960s and efforts undertaken at the time to understand them. Since then, individual protest movements have periodically emerged and scholars have responded with analytical treatments of them. The Arab Spring is one such event (Klein et al. 2018). The contemporary political context provides ample material for ongoing work.

As techniques become available from other fields, such as decision theory, aspects of behaviour that could not be treated or could only be treated in a general fashion before have been studied with more intensity. The emotions of the protesters or demonstrators is one such example (Flacks 1967; Orbell 1967; McPhail 1971; Paige 1971; Orum 1974; Jasper 1998, 2014). More generally, recent work in social psychology has brought together various factors, including emotions, grievances, efficacy, identity and social embeddedness, along with cognitive-rational-instrumental factors in dual pathway models that explain the choice to protest (Simon et al. 1998; Stürmer et al. 2003; van Steckelenburg et al. 2013).

The interactions between social movements and counter-movements has been less studied than protest behaviour and collective action in general, especially where the collective action is aimed towards the state (Meyer et al. 1996; Amenta et al. 2019). This is primarily due to the traditional focus of researchers on the origins of social movements, rather than other characteristics such as organisational form, the emergence of counter-movements and the dynamic interaction between opposing groups (Snyder et al. 1979; McAdam et al. 1988). It is possible that crowd counting organisations, which might themselves be a part of certain social movements and the data that they disseminate, can help researchers add another dimension to this longstanding and important academic conversation. The applications of decision theory, which are already embedded within this conversation, point towards the possibility of deeper connections between relative crowd sizes and the decision to organise and participate. How important these connections are to the dynamics of social movements is a matter for future research.

\section{Concluding remarks}

To contexts where turnout at events, whatever they may be, is an important consideration, crowd counting organisations are a new and potentially disruptive arrival. Studying their emergence and the data that they make available promises to reveal more than just broad

\footnotetext{
16 It should be noted that 'opportunity structure' for protest was a feature of the literature as early as the 1970 s, though without the rational choice component (see Eisinger 1973; Tilly 1978).

17 Of course, developments continued to be placed upon these foundations. For example, see Marsh (1977) and Loftland (1985).
} 
macro-level trends. To the extent that relative crowd size is important to decisions whether to organise/attend/watch/participate, expectations of gains and losses relative to a reference point-which might be a previous turnout, an opponent's turnout or an aspirational turnout - shape that decision. Since the possible reference points that we have identified are at least peripherally based on data of some sort, the availability of crowd size data, even for smaller, local events is a development that could have far-reaching implications. Combined with other social metrics and datasets, developments in crowd counting can help us trace some of the deeper narratives of human behaviour in contexts where relative crowd sizes are a feature of the decision-maker's evaluation of his or her alternative courses of action. The emergence of the crowd counting organisations themselves might also become the subject of empirical analysis, supported by some combination of orthodox and behavioural decision theory.

Funding No funding was received for this paper.

\section{Compliance with Ethical Standards}

Conflict of interest statement The authors declare no conflict of interest.

\section{References}

ABC News. St Kilda Beach Far Right Rally Draws Hundreds of Melbourne Police, Rival Protesters. January 5 2019. https://www.abc.net.au/news/2019-01-05/far-right-rally-in-st-kilda/10686966

Aljazeera 2018. Counter-Protesters Outnumber Far Right AFD Rally in Berlin. May 27. https://www.aljaz eera.com/news/2018/5/27/counter-protesters-outnumber-far-right-afd-rally-in-berlin

Allen, N: White Nationalists Drowned Out by Counter-Protesters in Washington Rally. Telegraph UK, May 13. (2018)

Amenta, E., Polletta, F.: The cultural impacts of social movements. Annual Review of Sociology. 45, 11.111.21 (2019)

Andrews, K.T.: Movement-Countermovement Dynamics and the Emergence of New Institutions: The Case of White Flight Schools in Mississippi. Soc. Forces 80, 911-936 (2002)

Ashenfelter, O., Johnson, G.E.: Bargaining Theory, Trade Unions and Industrial Strike Activity. American Economic Review 59, 35-49 (1969)

Baltimore Sun: Pro-Choice, Anti-Abortion Protesters Clash in N.Y. September 30 (1991).

Barberis, N.C.: Thirty Years of Prospect Theory in Economics: A Review and Assessment. Journal of Economic Perspectives 27, 173-196 (2013)

Barberis, N.C.: Richard Thaler and the Rise of Behavioural Economics. Scandinavian Journal of Economics 120, 661-684 (2018)

BBC News. 2019. Red Scarves March in Paris Against Yellow Vest Violence. January 27, 2019. https:// www.bbc.com/news/world-europe-47022456

Becker, G.: Crime and Punishment: An Economic Approach. Journal of Political Economy 76, 169-217 (1968)

Benford, R.D., Snow, D.A.: Framing Processes and Social Movements: An Overview and Assessment. Ann. Rev. Sociol. 26, 611-639 (2000)

Boulding, K.E.: Towards a Theory of Protest. ETC A Review of General Semantics. 24, 49-58 (1967)

Boston University. 2017. Counting American Protests. https:/www.bu.edu/research/articles/counting-ameri can-protests/

Card, D., Olson, C.A.: Bargaining Power, Strike Durations and Wage Outcomes: An Analysis of Strikes in the 1880s. Journal of Labour Economics 13, 32-61 (1995)

CBS News. 2019. Women's March NYC Draws Counter-Demonstration, Cries of Anti-Semitism. January 19. https://newyork.cbslocal.com/2019/01/19/womens-march-nyc-anti-semitism/ 
Chamberlin, J.: Provision of Collective Goods as a Function of Group Size. American Political Science Review 68, 707-716 (1974)

Chenoweth, E., Putnam, L., Pressman, J. \& Perkins, N: Media Coverage has Blown Anti-Lockdown Protests Out of Proportion. Vox, May 10. (2020)

Dambeck, H: Corona-Proteste in BerlinFaktencheck zur Teilnehmerzahl. Der Spiegel, August 30. (2020)

Denardo, J.: Power in Numbers: The Political Strategy of Protest and Rebellion. Princeton University Press, Princeton, NJ (1985)

Eisinger, P.K.: The Conditions of Protest Behavior in American Cities. American Political Science Review 67, 11-28 (1973)

Ferree, M.M., Miller, F.D.: Mobilisation and Meaning: Toward and Integration of Social Psychological and Resource Perspectives on Social Movements. Sociological Inquiry 55, 38-61 (1985)

Finkel, S.E., Muller, E.N.: Rational Choice and the Dynamics of Collective Political Action: Evaluating Alternative Models with Panel Data. American Political Science Review 92, 37-49 (1998)

Flacks, R.: The Liberated Generation: An Exploration of the Roots of Student Protest. Journal of Social Issues 23, 52-75 (1967)

Francisco, R.A.: Theories of Protest and the Revolutions of 1989. American Journal of Political Science 37, 663-680 (1993)

Frohlich, N., Oppenheimer, J.A.: I Get By With A Little Help From My Friends. World Politics 23, 104-120 (1970)

Gamson, W.A.: The Strategy of Social Protest. Dorsey, Homewood, Ill. (1975)

Garland, H.: Relation of effort-performance expectancy to performance in goal-setting experiments. J. Appl. Psychol. 69, 79-84 (1984)

Gleditsch, K.S., Rivera, M.: The Diffusion of Non-Violent Campaigns. J. Conflict Resolut. 61, 1120-1145 (2015)

Haas, M.L.: Prospect Theory and the Cuban Missile Crisis. Int. Stud. Quart. 45, 241-270 (2001)

Hardin, R.: Collective Action. Johns Hopkins University Press, Baltimore (1982)

Heath, C., Larrick, R.P., Wu, G.: Goals as Reference Points. Cogn. Psychol. 38, 79-109 (1999)

Herkenrath, M., Knoll, A.: Protest Events in International Press Coverage: An Empirical Critique of CrossNational Conflict Databases. Int. J. Comp. Sociol. 52, 163-180 (2011)

Hucal, S: Tensions High in Germany Where Far Right Protests on Thursday Will Be Met With Counter Demonstrations. ABC News America, August 30. (2018)

Irish Times. Belfast Yellow Vest Protest Derailed by Counter-Demonstration. January 19, 2019.

Jasper, J.M.: The Emotions of Protest: Affective and Reactive Emotions in and Around Social Movements. Sociol. Forum 13, 397-424 (1998)

Jasper, J.M.: Constructing Indignation: Anger Dynamics in Protest Movements. Emotion Review 6, 208213 (2014)

Kahneman, D., Tversky, A.: Prospect Theory: An Analysis of Decision Under Risk. Econometrica 47, 263291 (1979)

Karklins, R., Petersen, R.: Decision Calculus of Protesters and Regimes: Eastern Europe 1989. Journal of Politics 55, 588-614 (1993)

Kennan, J.: The Economics of Strikes. In: Ashenfelter, O., Layard, R. (eds.) Handbook of Labour Economics, vol. 1091. NorthHolland, New York (1986)

Klein, G.R., Regan, P.M.: Dynamics of Political Protests. International Organisation 72, 485-521 (2018)

Klein, H.J.: Further evidence on the relationship between goal setting and expectancy theory. Organ. Behav. Hum. Decis. Process. 49, 230-257 (1991)

Kluegel, J., Smith, E.R.: Affirmative Action Attitudes: Effects of Self Interest, Racial Affect and Stratification Beliefs. Soc. Forces 61, 787-824 (1983)

Koopmans, R.: The Dynamics of Protest Waves: West Germany 1965 to 1989. Am. Sociol. Rev. 58, 637658 (1993)

Lane, R.: Political Ideology. Free Press, New York (1962)

Leighley, J.E.: Attitudes, Opportunities and Incentives: A Field Essay on Political Participation. Political Research Quarterly 48, 181-210 (1995)

Levy, J.S.: Prospect Theory and International Relations: Theoretical Applications and Analytical Problems. Political Psychology 13, 283-310 (1992)

Levy, J.S.: Loss Aversion, Framing and Bargaining: The Implications of Prospect Theory for International Conflict. International Political Science Review 17, 179-195 (1996)

Levy, J.S.: Prospect Theory, Rational Choice and International Relations. Int. Stud. Quart. 41, 87-112 (1997)

Lipsky, M.: Protest as a Political Resource. American Political Science Review 62, 1144-1158 (1968)

Loftland, J.: Protest. Transaction Publishers, New Brunswick NJ (1985) 
Lopes, L.L.: Between Hope and Fear: The Psychology of Risk. Adv. Exp. Soc. Psychol. 20, 255-295 (1987)

Luders, J.: The Economics of Movement Success: Business Responses to Civil Rights Mobilisation. Am. J. Sociol. 111, 963-998 (2006)

Marsh, A.: Protest and Political Consciousness. Sage Publications, Beverly Hills CA (1977)

Marx, G.T.: Protest and Prejudice: A Study of Belief in the Black Community. Harper \& Row, New York (1967)

Mattick, H.W.: The Form and Content of Recent Riots. University of Chicago Law Review 35, 660-685 (1968)

McAdam, D., McCarthy, J.D. \& Zald, M.N: Social Movements. In: Neil J. Smelser. (eds.) Handbook of Sociology, Newbury Park, vol. 695-737. California, Sage (1988)

McDermott, R.: Prospect Theory in International Relations: The Iranian Hostage Rescue Mission. Political Psychology 13, 237-263 (1992)

McGuire, M.C.: Group Size, Group Homogeneity and the Aggregate Provision of a Pure Public Good Under Cournot Behaviour. Public Choice 18, 107-126 (1974)

McInerney, A.: Prospect Theory and Soviet Policy Towards Syria, 1966-1967. Political Psychology 13, 265-282 (1992)

McPhail, C.: Civil Disorder Participation: A Critical Examination of Recent Research. Am. Sociol. Rev. 36, 1058-1073 (1971)

McPhail, C., McCarthy, J.: Who Counts and How: Estimating the Size of Protests. Contexts 3, 12-18 (2004)

Meyer, D.S., Staggenborg, S.: Movements, Countermovements and the Structure of Economic Opportunity. Am. J. Sociol. 101, 1628-1660 (1996)

Muller, E.N., Seligson, M.A.: Inequality and Insurgency. American Political Science Review 81, 425-452 (1987)

Muller, E.N., Weede, E.: Cross-National Variation in Political Violence: A Rational Action Approach. J. Conflict Resolut. 34, 624-651 (1990)

Muller, E.N., Dietz, H.A., Finkel, S.E.: Discontent and the Expected Utility of Rebellion. American Political Science Review 85, 1261-1282 (1991)

Myers, D.J.: The Diffusion of Collective Violence: Infectiousness, Susceptibility and Mass Media Networks. Am. J. Sociol. 106, 173-208 (2000)

Nakamura, D: Trailing in the Polls and in Fundraising, Trump Clings to One Marker as a Sign of Success Crowd Size. The Washington Post, October 18. (2020)

Oliver, P.E., Marwell, G.: The Paradox of Group Size in Collective Action: A Theory of Critical Mass II. Am. Sociol. Rev. 53, 1-8 (1988)

Olorunnipa, T., Boburg, S. \& Hernandez, A.R: Rallies Against Stay-at-Home Orders Grow as Trump Sides with Protesters. The Washington Post, April 18. (2020)

Olson, M.: The Logic of Collective Action: Public Goods and the Theory of Groups. Harvard University Press, Cambridge, Mass (1965)

Opp, K.: The Rationality of Political Protest. Westview, Boulder, CO (1989)

Orbell, J.M.: Protest Participation Among Southern Negro College Students. American Political Science Review 61, 446-456 (1967)

Orum, A.M.: On Participation in Political Protest Movements. Journal of Applied Behavioural Science 10, 181-207 (1974)

Paige, J.M.: Political Orientation and Riot Participation. Am. Sociol. Rev. 36, 810-820 (1971)

Parkin, F.: Class, Inequality and Political Order. Praeger, New York (1971)

PBS America 2018. Right Wing Rally, Counter-Protesters Face Off in Portland. April 4.

Pearlman, W.: Moral Identity and Protest Cascades in Syria. British Journal of Political Science 48, 877901 (2018)

Phillips, P.J., Pohl, G.: Prospect Theory and Terrorist Choice. Journal of Applied Economics 17, 139-160 (2014)

Pinard, M.: Poverty and Political Movements. Soc. Probl. 15, 25-263 (1967)

Reuters, : Fact Check: Crowd Size at Trump and Biden Events Reflect Campaign Strategy, p. 31. Not Support, Reuters, October (2020)

Richardson, L.: Avoiding and Incurring Losses: Decision-Making in the Suez Crisis. In: Stein, J., Pauly, L. (eds.) Choosing to Cooperate: How States Avoid Loss, pp. 170-201. Johns Hopkins University Press, Baltimore (1993)

Schelling, T.C.: The Strategy of Conflict. Harvard University Press, Cambridge, Mass (1960)

Schelling, T.C.: Dynamic Models of Segregation. Journal of Mathematical Sociology 1, 143-186 (1971)

Schelling, T.C.: Micromotives and Macrobehavior. W.W. Norton, New York (1978)

Shear, M.D. \& Kaplan, T: Both Candidates Agree: Trump's Crowds Are Bigger and They're OK with That. The New York Times, November 1. (2020) 
Simon, B., Loewy, M., Stürmer, S.: Collective Identification and Social Movement Participation. J. Pers. Soc. Psychol. 74, 646-658 (1998)

Snyder, D. \& Kelly, W.R: Strategies for Investigating Violence and Social Change. In: Mayer N. Zald and John D. McCarthy (eds.) The Dynamics of Social Movements. Cambridge, vol. 212. Mass, Winthrop (1979)

Spilerman, S.: The Causes of Racial Disturbances: A Comparison of Alternative Explanations. Am. Sociol. Rev. 35, 627-649 (1970)

Spilerman, S.: The Causes of Racial Disturbances: Test of an Explanation. Am. Sociol. Rev. 36, 427-442 (1971)

Spilerman, S.: Structural Characteristics of Cities and the Severity of Racial Disorders. Am. Sociol. Rev. 41, 771-793 (1976)

Stürmer, S., Simon, B.: The Dual-Pathway Model of Social Movement Participation: The Case of the Fat Acceptance Movement. Social Psychology Quarterly 66, 71-82 (2003)

Thaler, R.H.: Mental Accounting and Consumer Choice. Marketing Science 4, 199-214 (1985)

Thaler, R.H (2016) Misbehaving: The Making of Behavioural Economics. W.W. Norton: New York, New York.

Tilly, C.: From Mobilization to Revolution. Addison Wesley, Reading, Mass. (1978)

Tversky, A., Kahneman, D.: Advances in Prospect Theory: Cumulative Representation of Uncertainty. Journal of Risk and Uncertainty 5, 297-323 (1992)

van Steckelenburg, J., Klandermans, B.: The Social Psychology of Protest. Current Sociology Review 61, 886-905 (2013)

von Neumann, J., Morgenstern, O.: Theory of Games and Economic Behaviour. Princeton University Press, Princeton, NJ (1947)

Wilson, J.Q.: The Strategy of Protest: Problems of Negro Civic Action. J. Conflict Resolut. 3, 291-303 (1961)

Wilson, J.: Introduction to Social Movements. Basic Books, New York (1973)

Zeitlin, M.: Economic Insecurity and the Political Attitudes of Cuban Workers. Am. Sociol. Rev. 31, 31-51 (1966)

Publisher's Note Springer Nature remains neutral with regard to jurisdictional claims in published maps and institutional affiliations. 